\title{
Effect of aggregates and curing conditions on the compressive strength of concrete with age
}

\author{
Aminur M.R ${ }^{1}$, Harunur M.R ${ }^{2}$, Teo, D.C.L ${ }^{3}$ and Abu Zakir M.M ${ }^{2}$
}

\begin{abstract}
The present research describes the effect of aggregate and curing condition on the compressive strength of concrete with age. Ordinary Portland cement, coarse sand and brick chips/pebble gravels were used as binder, fine aggregate and coarse aggregate respectively. The ratio of cement, sand and coarse aggregate was 1:2:4 by weight. Five different curing conditions namely, water curing (WC), self curing (SC), air dry curing (ADC), one-day delay curing (1-DC) and three-days delay curing (3-DC) were employed. Two types of concrete namely; concrete $\mathrm{C} 1$ (brick chips as coarse aggregate) and $\mathrm{C} 2$ (pebbles gravel as coarse aggregate) were prepared in this study. The physical and mechanical properties of aggregates and concrete were determined respectively. The results show that, the compressive strength of concrete is affected by the properties of the aggregate and also curing condition employed. It was found that, the concrete $\mathrm{C} 1$ and the normal water curing appeared to be better than concrete $\mathrm{C} 2$ and other types of curing condition.
\end{abstract}

Keywords: Brick Chips, Curing period, Concrete, physical and mechanical properties.

\section{INTRODUCTION}

ONCRETE properties are considerably dependent of temperature and humidity especially during the curing period. The objectives of curing are to keep concrete saturated or nearly saturated to get the products of hydration of cement. The temperature of curing and the duration of moist curing are the key factors for proper curing [1].

Generally, concrete properties and durability are influenced by curing condition which greatly affects the hydration of cement. The hydration of cement virtually ceases when the relative humidity within capillaries drops below 80\% [2]. Under an efficient curing method such as water curing, the relative humidity is above $80 \%$, enabling the hydration of cement to continue [3]. Conversely, the concrete specimens lose water or moisture through evaporation and become dry in the absence of proper curing. When hydration stops, sufficient calcium silicate hydrate cannot develop from the reaction of cement compounds and water. Calcium silicate hydrate is the major strengthproviding reaction product of cement hydration [3]. It also acts as a porosity reducer and thereby results in a dense microstructure in concrete. Therefore, an efficient curing is inevitable to prevent the moisture movement or evaporation of water from concrete surface. This can be accomplished by keeping the concrete element completely saturated or as much saturated as possible until the water-filled spaces are substantially reduced by hydration products [4]. As the reactions proceed, the products of the cement hydration process gradually bond together the individual sand and gravel particles, and other components of the concrete, to form a solid mass. The chemical reaction that occurs is as follows:

Cement chemist notation: $\mathrm{C}_{3} \mathrm{~S}+\mathrm{H} \rightarrow \mathrm{C}-\mathrm{S}-\mathrm{H}+\mathrm{CH}$

Standard notation: $\mathrm{Ca}_{3} \mathrm{SiO}_{5}+\mathrm{H}_{2} \mathrm{O} \rightarrow(\mathrm{CaO})\left(\mathrm{SiO}_{2}\right)\left(\mathrm{H}_{2} \mathrm{O}\right)+\mathrm{Ca}(\mathrm{OH})_{2}$

Balanced: $2 \mathrm{Ca}_{3} \mathrm{SiO}_{5}+7 \mathrm{H}_{2} \mathrm{O} \rightarrow 3(\mathrm{CaO}) 2\left(\mathrm{SiO}_{2}\right) 4\left(\mathrm{H}_{2} \mathrm{O}\right)+3 \mathrm{Ca}(\mathrm{OH})_{2}$

The hydration process begins in the mixer and continues throughout the time the concrete reaches its ultimate strength. The rate of hydration is controlled by the quality and quantities of the cementitious materials present in the mix as well as by the environmental temperature and the availability of moisture in the mix [1]. Ultimately the concrete can achieve higher strength and greater resistance to physical or chemical attacks in aggressive environments. Therefore, a suitable curing method is essential in order to produce strong and durable concrete [5].

Several researchers [6-12] have discussed the effects of water and vapor curing conditions on the properties of concrete. However, in the desert area or where water is not readily available for curing purposes, the conventional curing method is not practiced and delayed curing may occur. Sometimes in the normal construction project, curing may also be delayed due to many factors. Consequently, this study concentrates on the effect of different types of curing conditions on the compressive strength. The main objective of this paper is to investigate the influence of various types of curing conditions on the compressive strength of concrete produced from different coarse aggregates. The performance of these concrete in terms of compressive strength is also compared.

${ }^{1}$ Master Student, Department of Civil Engineering, Faculty of Engineering, Universiti Malaysia Sarawak, 94300-Kota Samarahan, Sarawak, Malaysia, +6082583246, Email:aminur83@gmail.com

${ }^{2}$ Lecturer, Department of Civil Engineering, Faculty of Engineering, Khulna Universiti of Engineering and Technology, Khulna-920300, Bangladesh, Email:hafin02@yahoo.com

${ }^{3}$ Lecturer, Department of Civil Engineering, Faculty of Engineering, Universiti Malaysia Sarawak, 94300-Kota Samarahan, Sarawak, Malaysia, Email:tdelsye@feng.unimas.my 


\section{MATERIALS AND METHODOLOGY}

\subsection{MATERIALS AND CURING CONDITIONS}

In this study, locally available brick chips and pebble gravel were used as coarse aggregate, while coarse sand, was used as fine aggregate. Ordinary Portland cement was used as binder. Normal tap water was used in the mixing and curing process. The physical properties of coarse and fine aggregates are shown in Table 1. The unit weight of aggregates was done in accordance to ASTM C140-01 (2001) [13].

Table 1: Physical properties of aggregates

\begin{tabular}{|c|c|c|c|c|c|c|}
\hline \multicolumn{2}{|l|}{ Aggregate } & $\begin{array}{l}\text { Unit Weight } \\
\left(\mathrm{kg} / \mathrm{m}^{3}\right)\end{array}$ & $\begin{array}{l}\text { Absorption } \\
\text { capacity (\%) }\end{array}$ & $\begin{array}{l}\text { Specific } \\
\text { gravity }\left(G_{s}\right)\end{array}$ & $\begin{array}{l}\text { Fineness } \\
\text { modulus } \\
\text { (FM) }\end{array}$ & $\begin{array}{l}\text { Physical } \\
\text { appearance }\end{array}$ \\
\hline \multirow{2}{*}{$\begin{array}{l}\text { Coarse } \\
\text { aggregate }\end{array}$} & $\begin{array}{l}\text { Brick } \\
\text { chips }\end{array}$ & 1050 & 14.88 & 2.0 & 6.58 & $\begin{array}{l}\text { Rough } \\
\text { surface }\end{array}$ \\
\hline & $\begin{array}{l}\text { Pebble } \\
\text { gravel }\end{array}$ & 1770 & 0.53 & 2.66 & 6.68 & $\begin{array}{l}\text { Smooth } \\
\text { surface }\end{array}$ \\
\hline $\begin{array}{l}\text { Fine } \\
\text { aggregate }\end{array}$ & Sand & 1560 & 4.16 & 2.62 & 2.31 & -- \\
\hline
\end{tabular}

The sieve analysis and fineness modulus were also conducted according to ASTM C136-96a (1996) [14]. The absorption capacity and specific gravity of fine and coarse aggregates were performed as per ASTM C127 (2004) [15] and ASTM C192 (1996) [16] respectively. The particle size distributions of the aggregates are shown in Fig. 1.

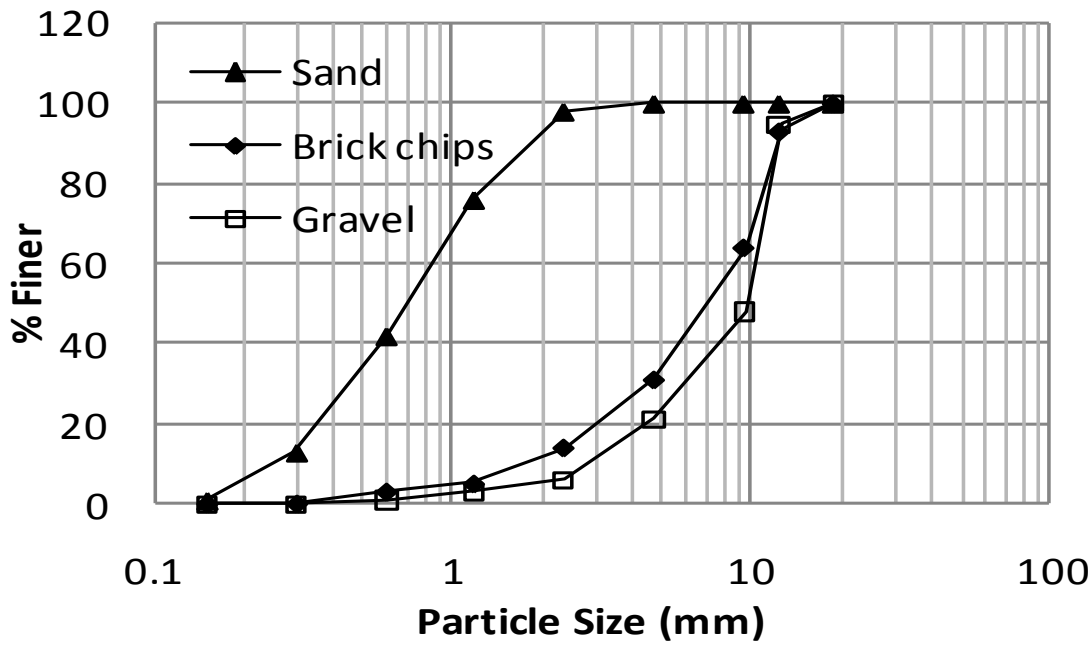

Fig. 1. Particle size distribution of aggregates

In this study, two types of concrete were produced namely $\mathrm{C} 1$ concrete (brick chips concrete) and $\mathrm{C} 2$ concrete (pebble gravel concrete) The ingredients of concrete $\mathrm{C} 1$ is brick chips, coarse sand, ordinary Portland cement and normal tap water whereas for $\mathrm{C} 2$ concrete, pebble gravel is used as coarse aggregate and other materials are the same as those used for the production of concrete C1. Saturated surface dry (SSD) condition brick chips were used in concrete $\mathrm{C} 1$ due to high absorption capacity. The ratio of cement, sand and aggregate was 1:2:4 by weight. The ingredients of concrete $\mathrm{C} 1$ and $\mathrm{C} 2$ are summarized in Table 2 .

Table 2: Concrete types and ingredient

\begin{tabular}{|l|l|l|}
\hline Concrete type & C1 (Brick chips concrete) & C2 (Pebble gravel concrete) \\
\hline Ingredient & $\begin{array}{l}\text { Brick chips, coarse sand, Ordinary } \\
\text { Portland cement and water }\end{array}$ & $\begin{array}{l}\text { Pebble gravel, coarse sand, Ordinary } \\
\text { Portland cement and water }\end{array}$ \\
\hline
\end{tabular}

Five types of curing conditions were employed to investigate the curing effect with age on mechanical properties of concrete. During the curing period, specimens were stored in five different curing environments until tested. For the sake of consistency, three specimens were tested and the average values taken. For 1-DC and 3-DC, specimens were left in the lab after demolding and immersed in water after one and three days respectively. In the case of air-dry curing, specimens were stored in laboratory environment (approximately $21-24^{\circ} \mathrm{C}$ ) after 7 days of WC. This curing method was also used by Malhotra, (1992) [11]. The detailed procedures of the five types of curing conditions are shown in Table 3. 
UNIMAS e-Journal of Civil Engineering, Vol. 1 (2) /April 2010

Table 3: Types of curing condition

\begin{tabular}{|c|c|c|c|}
\hline \multicolumn{2}{|l|}{ Curing condition } & \multirow{2}{*}{ Description } & \multirow{2}{*}{ Curing period (Days) } \\
\hline Type & Abbreviation & & \\
\hline Water curing & WC & Full submersion in water & \multirow{5}{*}{ Until the age of test } \\
\hline Self curing & $\mathrm{SC}$ & $\begin{array}{l}\text { Wrapped with three layers of } \\
\text { poly-film }\end{array}$ & \\
\hline Air dry curing & $\mathrm{ADC}$ & $\begin{array}{l}\text { Kept in room temperature } \\
\text { after } 7 \text { days of water curing }\end{array}$ & \\
\hline $\begin{array}{l}\text { One day delay } \\
\text { curing }\end{array}$ & $1-\mathrm{DC}$ & $\begin{array}{l}\text { Immersed in water after one } \\
\text { day of demoulding }\end{array}$ & \\
\hline $\begin{array}{l}\text { Three day } \\
\text { delay curing }\end{array}$ & 3-DC & $\begin{array}{l}\text { Immersed in water after three } \\
\text { days of demoulding }\end{array}$ & \\
\hline
\end{tabular}

\subsection{METHODOLOGY}

\subsubsection{SPECIMEN PREPARATION}

The brick chips and gravel were sieved and washed with normal tap water to remove dust and other foreign particles. The ingredients were mixed by using rotating type mixture machine (capacity 50 liter, Model 55-C197) as per BS1881: Part 125 (1881) [17]. The concrete specimens were cast into $100 \mathrm{~mm}$ diameter and $200 \mathrm{~mm}$ height cylindrical moulds. Compaction was conducted according to BS 1881: Part 108 (1983) [18]. Immediately after casting, the specimens were kept in a cool place and covered with a plastic sheet and wet burlap. The specimens were demoulded after of $24 \pm 2$ hours and cured accordingly.

\subsubsection{MECHANICAL PROPERTIES TEST}

The concrete compressive strength test was performed at 7, 28 and 90 days according to ASTM C39 (1986) [19]. Sulfur cap was used on the top and bottom of specimen to obtain smooth surface of the specimen during testing. The caps were used between 3-6 mm thicknesses and surface was flat and smooth. The cylindrical specimens placed accurately at centre position of the lower platen of the machine by using a spacing block. The upper platen was driven vertically downward to top of the specimen. Uniaxial load was applied uniformly at specified rate. The maximum load was displayed in the digital display. The compressive strength was calculated using the following equation 1 .

$$
\mathrm{Sc}=(\mathrm{F} / \mathrm{As}) \times 10^{3}
$$

Where Sc is the compressive strength (MPa), F is the applied load $(\mathrm{kN})$ and As is the area of cylindrical specimen $\left(\mathrm{mm}^{2}\right)$.

\section{RESULTS AND DISCUSSIONS}

\subsection{COMPRESSIVE STRENGTH}

The results of compressive strength for concrete $\mathrm{C} 1$ and $\mathrm{C} 2$ are shown in Figs. 2 to 5. From the figures, it can be seen that, the highest compressive strength value was found from WC condition at 90 days. From Fig. 2 it can be observed that, the compressive strength of specimens under delay curing (1-DC and 3-DC) are much lower compared to specimens under WC condition, especially at the earlier ages. However, at 90 days of the compressive strength of specimens under delay curing is almost similar to specimens cured under WC. This could be due to the internal curing provided by the brick chip aggregate since the aggregates were in SSD condition. The water stored within the aggregate may have acted as an internal reservoir which helps the cementitious hydration to continue even without proper curing. This ultimately improved the strength development of the specimens under 3-DC and 1-DC condition. From Fig. 2 it can also be observed that the compressive strength of specimens under SC for concrete $\mathrm{C} 1$ is higher than 3-DC up to 28 days of curing period, but after 28 days, 3 -DC is higher than SC.

In the case of concrete $\mathrm{C} 2$ as shown in Fig. 3, the compressive strength during early ages were closely similar. The development of good compressive strength for specimens under WC and 1-DC is credited to sufficient moisture, which maintained to continue the hydration of cement. This also indicated that the compressive strength of concrete was not influenced by the overall water content but rather by moisture movement in the concrete specimens [20;21]. However, the compressive strength of concrete C2 cured under 3-DC is lower than specimens cured under WC. It was also found that concrete $\mathrm{C} 2$ cured under 3-DC registered the lowest value. This could be due to the smooth surface of the pebble gravel which lowered the bonding capacity between the aggregate and the mortar and thus resulting in lower compressive strength. No internal curing was provided by this aggregate and this could also have affected the compressive strength. 


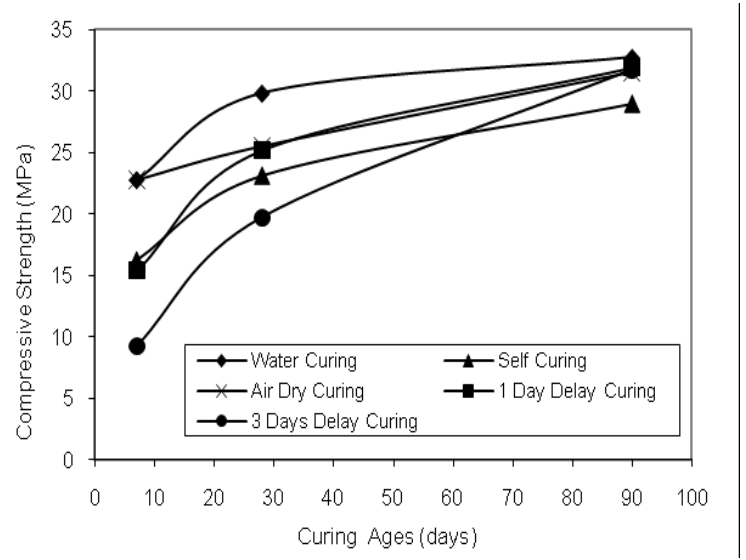

Fig: 2. Variation of compressive strength for concrete $\mathrm{C} 1$ under different curing conditions

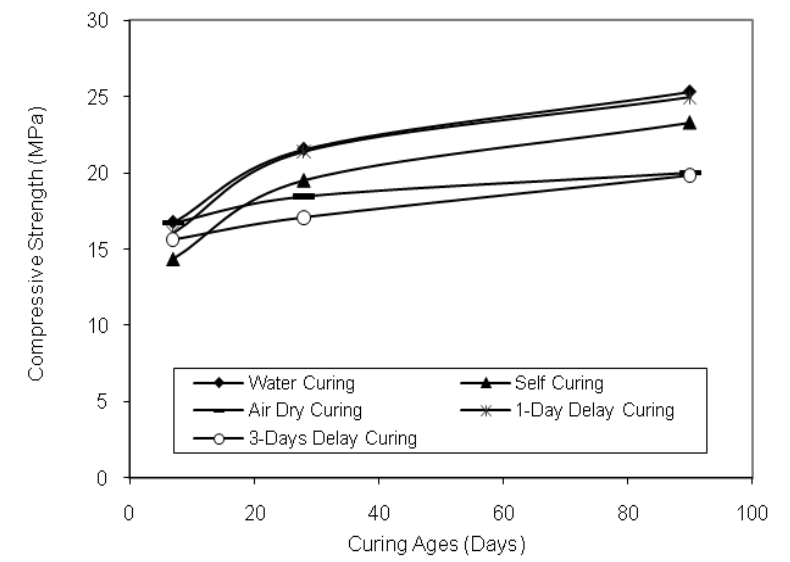

Fig: 3. Variation of compressive strength for concrete $\mathrm{C} 2$ under different curing conditions

In the case of concrete $\mathrm{C} 2$, the compressive strength of $\mathrm{ADC}$ is lower by approximately 26-36\% compared to concrete $\mathrm{C} 1$ under the same curing condition. This again could be due to the internal curing provided by the brick chips which resulted in higher compressive strength for concrete $\mathrm{C} 1$.

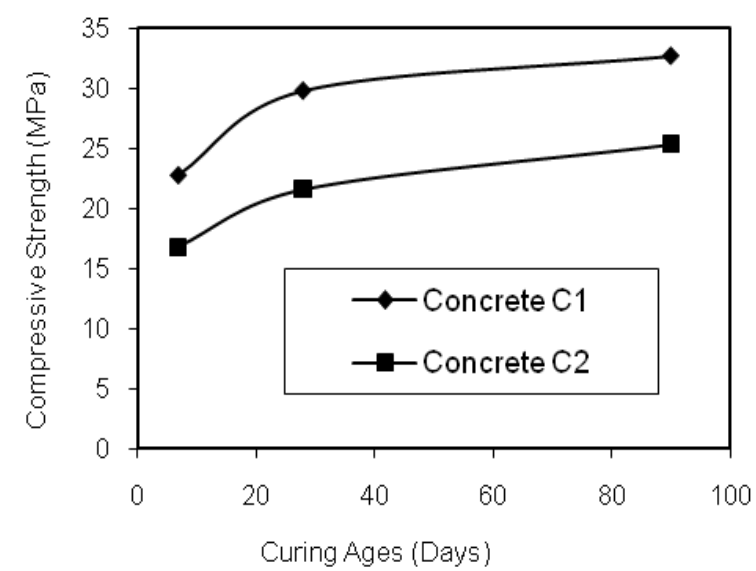

Fig: 4. Variation of compressive strength with curing period for concrete $\mathrm{C} 1$ and $\mathrm{C} 2$ under WC condition

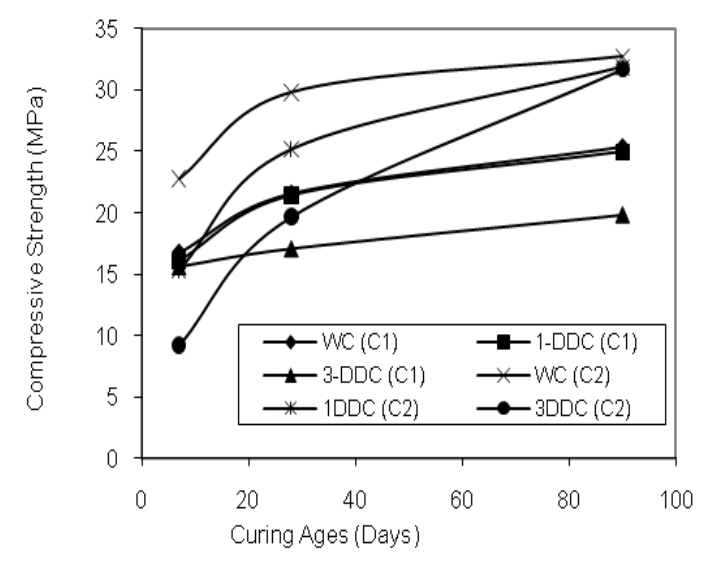

Fig: 5. Variation of compressive strength with curing period for concrete $\mathrm{C} 1$ and $\mathrm{C} 2$ under $\mathrm{WC}$ and delay curing conditions.

From Figs. 4 and 5 it can be clearly observed that the overall compressive strength of concrete $\mathrm{C} 1$ is better than concrete $\mathrm{C} 2$ and the water curing is better than other types of curing conditions. During the ADC curing period, the temperature and relative humidity (RH) were also recorded, which is presented in Figs. 6 and 7 respectively. The temperature and RH also may affect on the compressive strength of concrete. From Fig. 7 it can be observed that at the end of October (2005) the RH is high. As a result, the compressive strength of concrete $\mathrm{C} 1$ is almost similar with specimens under $\mathrm{WC}$ at 90 days. This could be due to absorbed moisture from surrounding environment.

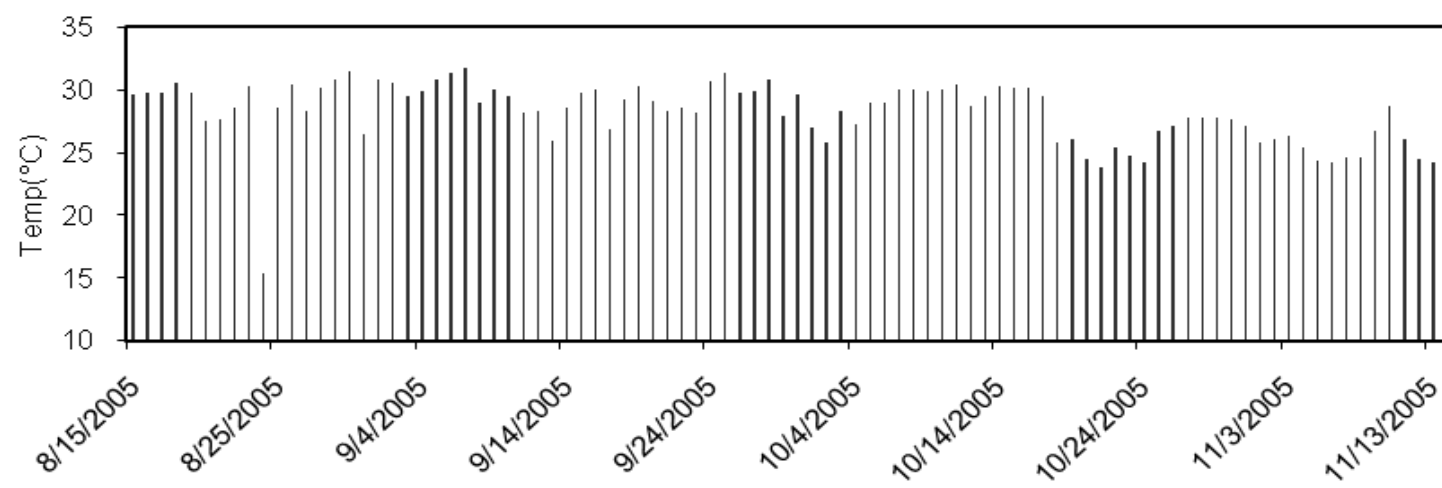

Ohserved time

Fig. 6: Variation of daily temperature during air dry curing 


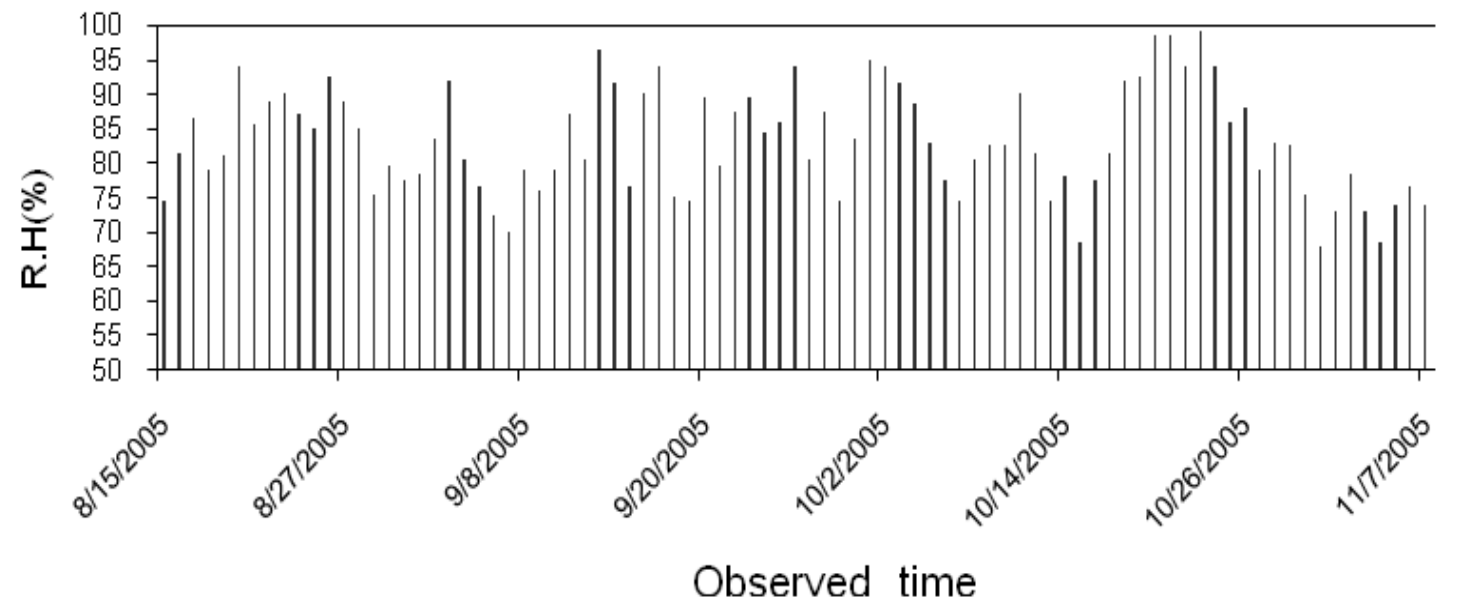

Fig. 7: Variation of relative humidity during air dry curing

\section{CONCLUSIONS}

From the results obtained in this research, the following conclusions can be drawn.

1. The compressive strength increases with an increase in curing period.

2. It was found that the compressive strength of concrete $\mathrm{C} 2$ is lower compared to concrete $\mathrm{C} 1$. This could be due to the rough surface of the brick chips which increased the bonding with mortar and ultimately increasing the compressive strength of concrete $\mathrm{C} 1$. Brick chips appear to be better compared to pebble gravel as aggregates for the production of higher strength concrete.

3. As expected, WC condition produced concrete with higher strength compared to the other types of curing conditions for both types of concrete. At 90 days, concrete $\mathrm{C} 1$ registered the lowest compressive strength under $\mathrm{SC}$ condition while concrete $\mathrm{C} 2$ cured under 3-DC condition produced the lowest compressive strength.

4. Aggregates with high water absorption values used in SSD condition for casting concrete is suitable for construction in areas with water shortage/problems or where delay curing is expected since the compressive strength of specimens under delayed curing are closely similar to those of well cured specimens, especially at the later ages.

\section{ACKNOWLEDGEMENTS}

The authors would like to acknowledge the department of Civil Engineering, Khulna University of Engineering and Technology (KUET) for financial support. In addition, the authors would like to express deep gratitude for the technical supports offered by the Concrete laboratory staff, KUET, Bangladesh.

\section{REFERENCES}

[1] M.A. Mannan , H.B. Basri, M.F.M. Zain, and M.N. Islam (2002). "Effect of curing conditions on the properties of OPSconcrete". Building and Environment, 2002, Vol. 37, pp. 1167-1171.

[2] A.M. Neville. Properties of concrete, 4th ed. London: Longman Group Limited, (1995).

[3] M. Safiuddin, S.N. Raman, and M.F.M. Zain. "Effect of Different Curing Methods on the Properties of Microsilica Concrete". Australian Journal of Basic and Applied Sciences, 2007, Vol. 1, No. 2, pp. 87-95.

[4] N. Gowripalan, J.G. Cabrera, and A.R. Cusens. "Wainwright, "Effect of Curing on Durability". Durable Concrete, ACI Compilation 24, American Concrete Institute, Farmington Hills, Michigan,USA, 2002, pp. 47-54.

[5] M.F.M. Zain, and Y. Matsufuji. "The Influence of Curing Methods on the Physical Properties of High Strength Concrete Exposed to Medium Temperature $\left(20-50^{\circ} \mathrm{C}\right)$ ”. In the Proceedings of the Fifth International Conference on Concrete Engineering and Technology, Kuala Lumpur, Malaysia, 1997.

[6] M. D. A., Thomas, J. D. Matthews and C. A. Haynes. "The effect of curing on strength and permeability of PFA concrete." In Proc. 3rd CANMETIACI Int. Conf on the Use of Fly Ash, Silica Fume, Slag, and Natural Pozzolans in Concrete, ed. V. M. MaIhotra. AC1 Special Publication SP-114, 1989, pp.191-217.

[7] K. Tan, and O.E. Gjorv, (1996). "Performance of concrete under different curing conditions." Cem. Concr. Res. 1996, Vol. 26, No.3, pp.355-361.

[8] P.C. Aitcin, B. Miao, W.D. Cook, and D. Mitchell. (1994). "Effect of size and curing on cylinder compressive strength of normal and high strength concretes.” ACI Mater. J. 1994, Vol. 9, No. 4, pp.349-354.

[9] S. Popovics. "Effect of curing method and final moisture condition on compressive strength of concrete." ACI J. 1986, Vol. 83, No. 4, pp.650-657.

[10] J.C. Chern, and Y.W. Chart. "Effect of temperature and humidity conditions on the strength of blast furnace slag cement concrete." In Proc. 3rd CANMETIACI Int. Conf on the Use of Fly Ash, Silica Fume, Slag, and Natural Pozzolans in Concrete, ed. V. M. Malhotra. AC1 Special Publication SP-114, 1989, pp.1377-1397.

[11] V. M., Malhotra. "CANMET investigation dealing with high-volume fly ash concrete." In Advances in Concrete Technology, Energy, Mines and Resources Canada, Ottawa, Division Report MSL, 1992, pp.433-70. 
[12] S.L. Wood. (1991). "Evaluation of the long-term properties of concrete.” ACI Mater. J. 1991, Vol. 88, No. 6, pp.630-643.

[13] ASTM C140-01. "Standard Test Methods for Sampling and Testing Concrete Masonry Units and Related Units.” Annual book of ASTM standards, 2001.

[14] ASTM C136-96a. "Standard Test Method for Sieve Analysis of Fine and Coarse Aggregates." Annual book of ASTM standards, 1996.

[15] ASTM C 127-04. "Standard Test Method for Density, Relative Density (Specific Gravity), and Absorption of Coarse Aggregate." Annual book of ASTM standards, 2004.

[16] ASTM C192. "Standard Practice for Making and Curing Concrete Test Specimens in the Laboratory." Annual book of ASTM standards, 1996.

[17] BS, Part 125. "Methods for mixing and sampling fresh concrete in the laboratory." British Standard Institution, London, 1881.

[18] BS, Part 108. "Method for making test cubes from fresh concrete". British Standard Institution, London, 1881.

[19] ASTM C-39. "Standard Test Method for Compressive Strength of Cylindrical Concrete Specimens." Annual Book of ASTM Standards, 1996, Vol.04.02.

[20] M.F. Zain. "The study on the physical properties of surface layer concrete under the influence of medium temperature environments". Ph.D. thesis, Faculty of Engineering, Kyushu University, Japan, 1995.

[21] M. Safiuddin (1998). "Influence of different curing methods on the mechanical properties and durability of high performance concrete exposed to medium temperature". M.Sc. thesis, Dept. of Civil and Structural Engineering, Universiti Kebangsaan Malaysia. 